\title{
Release of oxytocin and prolactin in response to suckling
}

\author{
ALAN S MCNEILLY, IAIN C A F ROBINSON, MARY J HOUSTON, PETER W HOWIE
}

\begin{abstract}
The oxytocin and prolactin responses to suckling were measured in 10 women in early $(n=5)$ and established lactation $(\mathbf{n}=5)$. Oxytocin was released in a pulsatile manner during suckling in all women, but the response was not related to milk volume, prolactin response, or parity of the mother. In all 10 women plasma oxytocin concentrations increased three to 10 minutes before suckling began. In five women this occurred in response to the baby crying, in three it coincided with the baby becoming restless in expectation of the feed, while in two it corresponded with the mother preparing for the feed. There was no prolactin response to stimuli other than stimulation of the nipple associated with suckling.

These results clearly indicate that the milk ejection reflex, with release of oxytocin, occurs in most women before the tactile stimulus of suckling. A second release of oxytocin follows in response to the suckling stimulus itself. Thus it is important that care is taken to protect breast feeding mothers from stress not only during suckling but also immediately before nursing, when conditioned releases of oxytocin will occur.
\end{abstract}

\section{Introduction}

The milk ejection reflex, in which oxytocin is released in response to suckling, appears to be essential for the baby to take milk from the breast. ${ }^{1}$ Despite this few studies on changes in blood oxytocin concentrations in response to suckling have been reported. Earlier studies in which intramammary pressure was recorded indicated that the rhythmic waves of intramammary pressure during suckling were best mimicked by

MRC Reproductive Biology Unit, University of Edinburgh Centre for Reproductive Biology, Edinburgh EH3 9EW

IAIN C A F ROBINSON, MA, DPHIL, research scientist

MRC National Institute for Medical Research, London NW7 1AA

ALAN S MCNEILLY, BSC, PHD, research scientist

MARY J HOUSTON, SCM, PHD, research sister (present address: John Radcliffe Hospital, Oxford OX3 9DU)

PETER W HOWIE, MD, FRCOG, consultant obstetrician (present address: Department of Obstetrics and Gynaecology, Ninewells Hospital, Dundee) discrete injections of oxytocin rather than constant infusions. ${ }^{2}$ This indicated that, as in animals, ${ }^{3}$ oxytocin is released in a pulsatile manner during suckling. This was substantiated by measurement of oxytocin in plasma in some studies ${ }^{4}$ but not in others. ${ }^{6} 7$

Lucas et al suggested that release of oxytocin may not be essential for satisfactory flow of milk during breast feeding because no oxytocin could be detected during suckling in some women. ${ }^{5}$ This conclusion must be viewed with extreme caution. In animals and women the milk ejection reflex may become conditioned to stimuli, such as the cry of the baby, as well as the physical action of suckling. ${ }^{13}$ Indeed, spontaneous ejections of milk occurring at regular intervals independent of suckling have been reported. ${ }^{8}$ No studies have investigated the patterns of release of oxytocin induced by stimuli occurring before suckling, and all previous investigations have been confined to mothers in the immediate postpartum period. Only a few reports are available correlating release of oxytocin to milk yield ${ }^{5}$ or the prolactin response to suckling. ${ }^{6}{ }^{7}$

We undertook the present study to measure the responses of oxytocin and prolactin before and during breast feeding in mothers in early (four to six days post partum) and established lactation (four and 10-11 weeks post partum).

\section{Patients and methods}

We studied the responses of oxytocin and prolactin to suckling in 10 volunteers who were breast feeding after delivering mature infants of normal birth weight in the Simpson Maternity Pavilion, Edinburgh. The table gives clinical details. Patients were studied only once: five were studied four to six days post partum, three four to five weeks post partum, and two 10 to 11 weeks post partum. Full informed consent was obtained from all the women before their inclusion in the study. All patients were feeding on demand, giving about six feeds in 24 hours, with feeds lasting four to 10 minutes on each breast. None of the patients had introduced any supplementary or complementary food.

All the observations were made during a feed occurring around 1200 , a catheter being placed in a forearm vein 40 minutes before the expected time of suckling. In all cases the baby remained with the mother, although before suckling it was held by one of the laboratory assistants helping with the blood collection. Blood samples $(10 \mathrm{ml})$ were withdrawn over $25-35 \mathrm{~s}$ into an ice cooled syringe and the samples transferred to lithium heparin tubes in ice. Plasma was separated by centrifugation at $4^{\circ} \mathrm{C}$ and stored in two separate aliquots at $-20^{\circ} \mathrm{C}$ until assayed. Blood samples were taken 15 minutes before 
Parity of mother, weight of baby at time of suckling, test weight of feed, and maximum plasma oxytocin concentration during sampling period and time when this occurred in relation to suckling

\begin{tabular}{ccccccc}
\hline $\begin{array}{c}\text { Case } \\
\text { No }\end{array}$ & Parity & $\begin{array}{c}\text { Age of } \\
\text { baby } \\
\text { (days) }\end{array}$ & $\begin{array}{c}\text { Weight of } \\
\text { baby } \\
\text { (g) }\end{array}$ & $\begin{array}{c}\text { Test } \\
\text { weight } \\
\text { (g) }\end{array}$ & $\begin{array}{c}\text { Maximum } \\
\text { plasma } \\
\text { oxytocin } \\
\text { (ng/l) }\end{array}$ & $\begin{array}{c}\text { Oxytocin } \\
\text { maximum } \\
\text { before or } \\
\text { during } \\
\text { suckling }\end{array}$ \\
\hline 1 & 2 & 4 & 3650 & 60 & 43 & Before \\
2 & 1 & 4 & 4158 & 52 & 11 & Before \\
3 & 2 & 4 & 4180 & 43 & 29 & Before \\
4 & 1 & 5 & 4380 & 42 & 11 & Before \\
5 & 1 & 6 & 3350 & 82 & 59 & During \\
6 & 1 & 28 & 4448 & 48 & 20 & Before \\
7 & 2 & 33 & 4400 & 73 & 29 & During \\
8 & 2 & 37 & 5600 & 161 & 12 & Before \\
9 & 1 & 75 & 7100 & 76 & 25 & During \\
10 & 2 & 81 & 6473 & 165 & 50 & Before \\
\hline
\end{tabular}

the start of suckling and then at one minute intervals from 10 minutes before until suckling ended 10-16 minutes after the start. A further sample was collected 10 minutes after the end of suckling. Because blood was being collected through a catheter that was led away from the mother the sampling procedure did not appear to intrude on the breast feed.

The volume of each feed was assessed by test weighing the baby before and after the feed with an electronic integrating balance as described previously. ${ }^{9}$ Oxytocin was measured by radioimmunoassay ${ }^{10}$ after extraction of the plasma using Sep-pak cartridges (Waters). Briefly, this entails absorption of acidified plasma samples on to C-18 Sep-pak cartridges, washing with $2 \mathrm{ml} 0 \cdot 1 \mathrm{~mol}$ formic acid, and eluting the oxytocin with $5 \mathrm{ml} 60 \%$ acetonitrile in $0.1 \mathrm{~mol}$ formic acid. The eluates were dried under a stream of air and stored at $-20^{\circ} \mathrm{C}$ until radioimmunoassay, when they were reconstituted in assay buffer. Recovery of oxytocin averaged $74 \pm \operatorname{SEM} 3 \%(n=7)$, and the results were corrected accordingly. Plasma prolactin concentration was measured by a specific radioimmunoassay ${ }^{11}$ using reagents supplied by Professor H G Friesen, Winnipeg, Canada. The interassay variation was $7.9 \%$; results were expressed in terms of units of MRC pituitary prolactin standard 75/504/1.

\section{Results}

Pattern of oxytocin release-Throughout the study oxytocin was detectable in most $(226 / 240)$ samples (range $1 \cdot 1-50 \cdot 3 \mathrm{ng} / 1$ ); in only
14 were the concentrations below the sensitivity $(<1.0 \mathrm{ng} / \mathrm{l})$ of the assay. The pattern of release was variable and pulsatile with, in some cases, raised concentrations returning to baseline values within one minute (figs 1 and 2). Maximum concentrations ranged between 11 and $59 \mathrm{ng} / \mathrm{l}$ and in seven of the 10 women occurred in samples taken before the start of suckling (table). Oxytocin concentration increased before suckling in all 10 women. In five these increases occurred just after the baby cried, three to 10 minutes before suckling (figs 1 (both cases) and 2 (case 6)), while in a further three they coincided with the baby becoming restless in expectation of the feed. In the remaining two they occurred as the mother prepared for nursing. In all cases oxytocin concentration increased in response to suckling, although this response was more consistent at four and 11 weeks post partum than in the immediate puerperium. In nine of the 10 women this increase was followed by a pronounced increase in the pulsatile release of oxytocin, while in one release of oxytocin was sustained without apparent pulses over the entire period of suckling. There was no correlation between the amount of oxytocin released and parity of the mother or volume of milk taken at the feed. All milk yields (table) were within the range expected. ${ }^{9}$

Prolactin release-Before suckling plasma prolactin concentrations were high immediately post partum (range 3.4-11.6 U/1) and decreased with time post partum (four to six weeks, range $0.7-1.4 \mathrm{U} / 1 ; 10-11$ weeks, $0 \cdot 6-1 \cdot 3 \mathrm{U} / 1$ ). While there was evidence of a pulsatile pattern of release of prolactin before suckling in some women (for example, cases 2 and 9 (figs 1 and 2)) there was no change in concentrations in response to any stimulus before suckling. In eight of the 10 women prolactin concentrations increased between one and four minutes after the start of suckling and continued to increase after the end of suckling (figs 1 and 2). There was no correlation between the release of prolactin and release of oxytocin or milk volume. In two patients (cases 5 and 10) there was no prolactin response to suckling.

\section{Discussion}

These results clearly indicate that suckling causes the release of both oxytocin and prolactin and that oxytocin is released in a pulsatile pattern. This confirms one previous investigation ${ }^{5}$ but contrasts with others that failed to show a pulsatile episodic pattern of oxytocin release. ${ }^{6}$ " In the latter reports, however, samples were collected only at two to five minute intervals, which, with the short half life of oxytocin, would be insufficient to show such a pulsatile pattern. Nevertheless, there is agreement
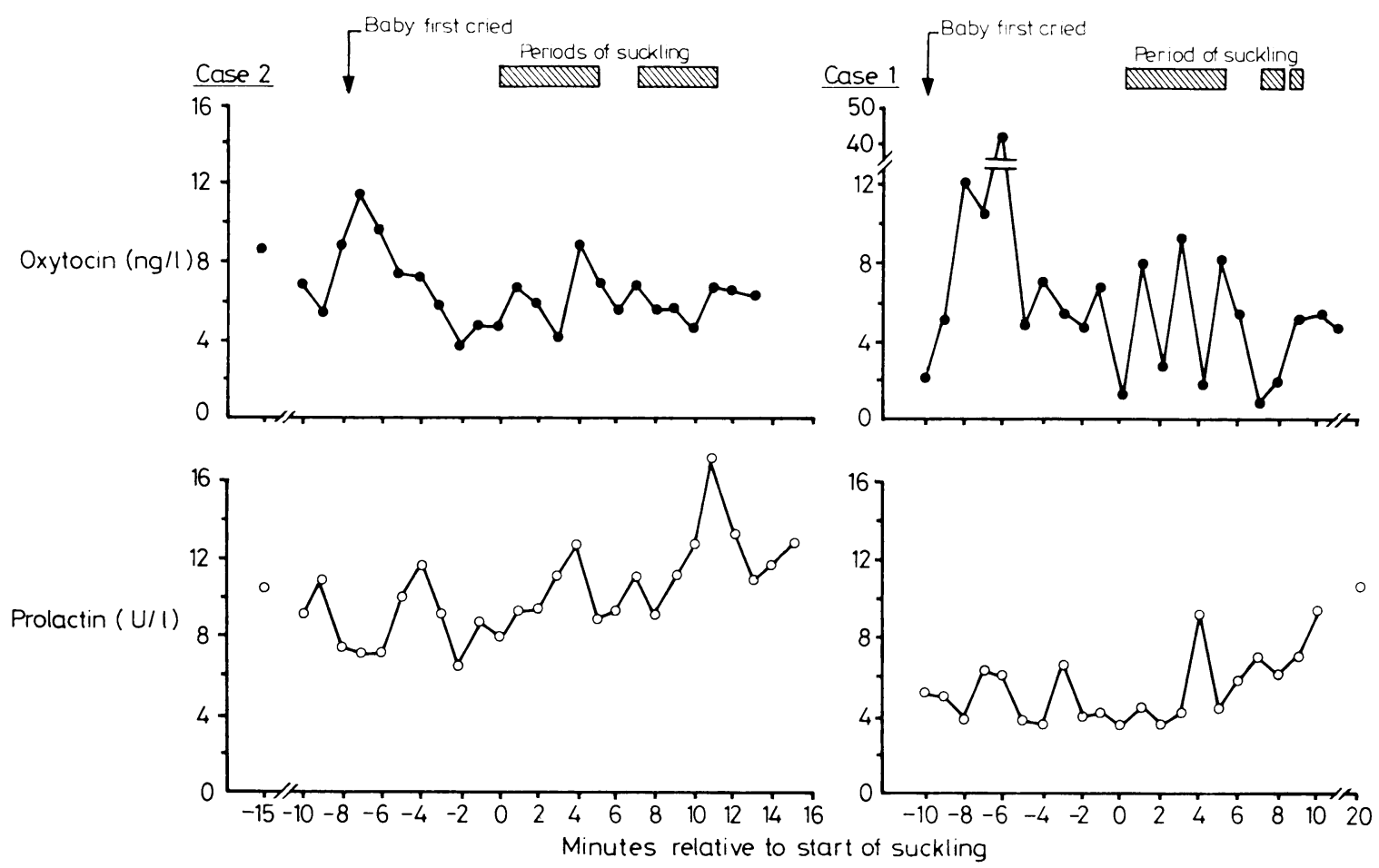

FIG 1 -Changes in plasma oxytocin $(\circlearrowleft)$ and prolactin $(\circlearrowleft)$ concentrations before and during suckling in two women on day 4 post partum. 


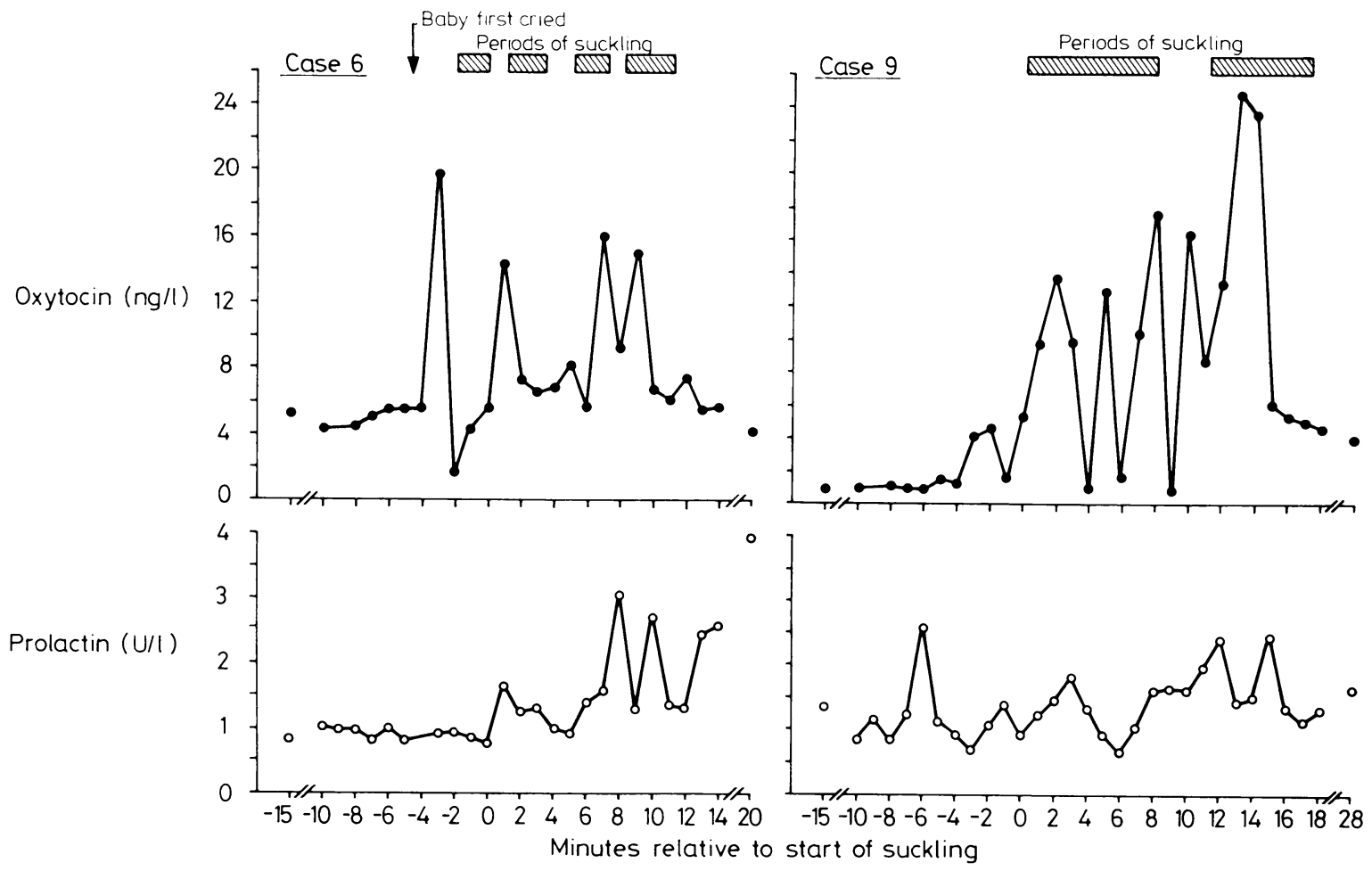

FIG 2-Changes in plasma oxytocin ( $)$ and prolactin $(O)$ concentrations before and during suckling 28 days (case 6 ) and 75 days (case 9) post partum.

that, in most women, suckling induces an increase in plasma oxytocin concentrations.

Of major importance in the present study, however, was the clear demonstration that oxytocin is normally released before the start of suckling. Lucas et $a l^{5}$ suggested that, because they failed to detect any change in oxytocin concentrations in three of their 10 patients during suckling and because the timing of the release of oxytocin did not always coincide with peak milk flow, release of oxytocin may not be essential for satisfactory transfer of milk from mother to child. In their study, however, insufficient samples were taken before the baby had fixed on the breast to determine whether release of oxytocin before suckling had occurred. From our results it appears that release of oxytocin occurs in most women before suckling begins. Possibly the primary function of sucking by the baby is removal of milk while release of oxytocin is a secondary effect. This has been reported in other species. ${ }^{13}$ In women spontaneous ejection of milk may occur independently of suckling, ${ }^{8}$ and this has been recognised by mothers for generations. Our failure to find a correlation between the amount of oxytocin released and the volume of milk may not be surprising. The amount of milk removed depends not necessarily on the volume of milk present in the breast but on the amount that the baby wishes to take. This, and the rate at which the milk is taken, varies widely between subjects, ${ }^{12}$ and our failure to find a correlation between release of prolactin and milk volume confirms our previous report. ${ }^{9}$ Indeed, the lack of a response of prolactin to suckling in two out of 10 women confirms other observations (A Glasier, A S McNeilly, and P W Howie, unpublished observations) that the response of prolactin to suckling in the morning is considerably reduced or even absent compared with that in the afternoon or evening. We also failed to see any response of prolactin to stimuli other than direct stimulation of the nipple, confirming previous reports. ${ }^{13}$

The present results support the concept that the milk ejection reflex, including release of oxytocin, is essential for the transfer of milk from mother to baby in breast feeding. An important part of this reflex is a conditioned release of oxytocin that occurs before the start of suckling. Ejection of milk associated with suckling may be inhibited by both physical and psychological stress, and women are more susceptible to these stresses in early lactation. ${ }^{1{ }^{14}}$ Clearly, care must be taken to protect breast feeding mothers from stress not only at the time of suckling but also immediately before nursing, when conditioned releases of oxytocin may occur.

Requests for reprints should be sent to Dr A S McNeilly.

\section{References}

${ }^{1}$ McNeilly AS. Physiology of human lactation. F Biosoc Sci 1977;4:5-21 ${ }^{2}$ Cobo E. Neuroendocrine control of milk ejection in women. In Josimocrich JB, Reynolds M, Cobo E, eds. Lactogenic hormones, fetal nutrition and lactation. New York: John Wiley and Sons, 1974:433-52.

3 Tindal JS. Neuroendocrine control of lactation. In: Larson BL, ed. Lactation. New York and London: Academic Press, 1978:67-114.

${ }^{4}$ Fox CA, Knaggs GS. Milk ejection activity (oxytocin) in peripheral venous blood in man during lactation and in association with coitus. f Endocrinol $1969 ; 45: 145-6$.

${ }^{5}$ Lucas A, Drewett RB, Mitchell MD. Breast feeding and plasma oxytocin concentrations. Br Med f 1980;281:834-5.

6 Weitzman RE, Leake RD, Rubin RT, Fisher DA. The effect of nursing on neurohypophyseal hormone and prolactin secretion in human subjects. $\mathcal{f}$ Clin Endocrinol Metab 1980;51:836-9.

${ }^{7}$ Dawood MY, Khan-Dawood FS, Wahl RS, Fuchs F. Oxytocin release and plasma anterior pituitary and gonadal hormones in women during lactation. 7 Clin Endocrinol Metab 1981 ;52:678-83.

${ }^{8}$ McNeilly AS, McNeilly JR. Spontaneous milk ejection during lactation and its possible relevance to success of breast-feeding. $\mathrm{Br} \mathrm{Med} \mathcal{F} 1978$ ii :466-8.

${ }^{9}$ Howie PW, McNeilly AS, McArdle T, Smart L, Houston M. The relationship between suckling-induced prolactin response and lactogenesis. F Clin Endocrinol Metab 1980;50:670-3.

${ }^{10}$ Robinson ICAF. The development and evaluation of a sensitive and specific radioimmunoassay for oxytocin in unextracted plasma. $f$ Immunoassay 1980;1:323-47.

${ }^{11} \mathrm{McNeilly}$ AS, Hagen C. The prolactin, LH, FSH and TSH response to a combined LHRH/TRH test in normal male subjects and during the menstrual cycle. Clin Endocrinol 1974;3:427-35.

12 Howie PW, Houston MJ, Cook A, Smart L, McArdle T, McNeilly AS How long should a breast feed last? Early Hum Dev 1981;5:71-7.

13 Noel GL, Suh HK, Frantz AG. Prolactin release during nursing and breast stimulation in post partum and non-postpartum subjects. $\mathcal{F}$ Clin Endocrinol Metab 1974;38:413-9.

14 Newton N, Newton M. The let down reflex in human lactation. $\mathcal{F}$ Pediatr $1948 ; 33: 1179-88$.

(Accepted 18 November 1982) 